\title{
Application of 3D Electrical Resistivity Tomography for Diagnosing Leakage in Earth Rock-Fill Dam
}

\author{
Xin Zhang, Mingjie Zhao, Kui Wang, Pan Liu, Huan Liu \\ School of River \& Ocean Engineering, Chongqing Jiaotong University, Chongqing, China \\ Email: 406328338@qq.com
}

Received 20 April 2016; accepted 14 May 2016; published 17 May 2016

Copyright (C) 2016 by authors and Scientific Research Publishing Inc.

This work is licensed under the Creative Commons Attribution International License (CC BY). http://creativecommons.org/licenses/by/4.0/

(c) (i) Open Access

\begin{abstract}
The leakage occurs during operation of the dam in Liuhuanggou reservoir. It's a threat to the safety of the people's lives and property in downstream. In order to eliminate the hidden danger of reservoir, ensure the safety of the dam, play better the function of flood control and water storage of the reservoir etc., we apply the 3D electrical resistivity tomography detecting technology and volume rendering image processing technology, make the measurement in field, process the data and combine the field survey to find out the leakage channels inside the dam. The results show that the 3D resistivity images appear the low resistivity zone corresponding with the leakage channels. There are two main leakage channels that come from different location inside the dam. It is feasible to diagnose the leakage in earth rock-fill dam by applying $3 \mathrm{D}$ electrical resistivity tomography.
\end{abstract}

Keywords

Earth Rock-Fill Dam, Leakage, 3D Electrical Resistivity Tomography, Volume Rendering

\section{Introduction}

Early electrical resistivity tomography (ERT) is 1D and divided into electrical sounding and electrical profile. The vertical electrical and horizontal electrical changes in different underground depth are reflected by the two methods respectively. They can obtain the geoelectric data too little to reflect the complicated geological conditions. With the development of CT imaging technology, some scholars have applied the technique of tomography to electrical exploration. Loke, M.H. [1] used quasi Newton method to improve the speed of calculation of the least square method; Feng Rui [2], the electrical resistivity tomography technology is applied to the hydro- 
geological investigation which has achieved good results; J.E. Chambers [3] estimated river sand and gravel deposits by using 3D electrical resistivity tomography. It shows that electrical resistivity tomography technology has developed rapidly and used widely in the field. 3D electrical resistivity tomography can obtain more data than 2D. 2D electrical resistivity tomography only can obtain information along the survey line direction, but 3D electrical resistivity tomography can obtain information in horizontal and vertical direction, and using the volume rendering image processing technology the more accurate results can be got. Zhou Xiaoxian [4], by comparing 2D and 3D observation experiment, the results show that the resolution of 3D electrical resistivity tomography is obviously better than the 2D; Shi Longqing [5], the water rich state of the working floor is analyzed by using horizontal and vertical slice in 3D electrical resistivity tomography. This leads to electrical resistivity tomography which has developed gradually from 2D to 3D.

Flood and drought disasters occur frequently that cause heavy losses in China in recent years, and the irrigation and water conservancy infrastructure are exposed very weak. We must vigorously strengthen the construction of water conservancy. We must consolidate the reinforcement results of large and medium-sized dangerous reservoirs, and speed up the reinforcement pace of small dangerous reservoirs, as soon as possible to eliminate the hidden danger of reservoirs, recover the control capacity of flood, and enhance the regulation capacity of water resources. China plans to reinforce the water conservancy project that has been the built during the period of "the 13th Five-year". Within the next two years, China's average annual investment is expected to reach 600 billion. This series of measures for the normal operation of the national economy and the guarantee of national sustainable development has played an important role, but also makes full use of the comprehensive benefits of the water conservancy facilities for flood control, irrigation, power generation etc. In a word, the state pays more attention to water conservancy project reinforcement. The leakage is a common dangerous in earth rock-fill dam. Through access to literature, we find that many water conservancy projects are not properly dealt with the leakage problem results in a series of accidents. The problem of the leakage in the dam is more and more serious in Liuhuanggou reservoir, and the space distribution of the leakage channel is understood by 3D electrical resistivity tomography detection technology, which provides a scientific basis for the next step of the treatment [6] [7].

\section{Theory of 3D Electrical Resistivity Tomography}

The theory of 3D electrical resistivity tomography is consistent with the common electrical method that conductive of underground material differences as the prerequisite, make underground is full of electricity and observe of subsurface electric field distribution, so as to solve different geological problems. Compared with 3D electrical resistivity tomography the 2D high-density electrical resistivity tomography still exist some problems: when the survey line doesn't layout in the hidden the underground objects cannot be reflected, which brought difficulty in field test and there is more difficult to detect complex leakage channels especially; Accuracy also have difference by using several 2D cross sections at the same time in an interface to open for forming a quasi 3D images between obtained true 3D images after 3D inversion. The 3D inversion divided the subsurface into a number of small rectangular to build geoelectric model [8], and give the initial value of each small rectangle, the resistivity value of each small rectangular volume is obtained by forward calculation, then use the least square method to compare the theoretical value and the measured value to adjust the resistivity of each sub block [9] [10]. Establish objective function $F$ :

$$
F=\sum_{i=1}^{N}\left[\ln \rho_{m}-\ln \rho_{t}\right]^{2}
$$

where: $\rho_{m}$ is the measured resistivity value of the profile; $\rho_{t}$ is the theoretical resistivity value of the initial model.

Comparing the accuracy between the measured resistivity value and the theoretical value to determine the results of the inversion calculation if it meets the requirements. When the requirements don't meet, it is required to recalculate the theoretical value until the difference is in the proper range.

\section{Application Example}

\subsection{Engineering Survey}

Reservoir locate in Jinping village the town of Tiaoshi Chongqing Banan district, dam locate in YiPing Rive the 
primary tributary of Yangtze River in the right bank. Liu Huanggou reservoir is type of a small (2) water conservancy project with flood control and irrigation. $0.2 \mathrm{~km}^{2}$ control basin area in Liu Huanggou reservoir, the main river channel length $0.8996 \mathrm{~km}$, average down more than 95.92 per thousand. Dam is a homogeneous earth dam, with the maximum dam height $13.25 \mathrm{~m}$, total capacity 14.06 million $\cdot \mathrm{m}^{2}$, normal storage capacity 12.46 million $\cdot \mathrm{m}^{2}$, dead storage 0.51 million $\cdot \mathrm{m}^{2}$, designed irrigation area 980 acres, the effective irrigation area 900 acres. The reservoir for V small (2) water conservancy project, the permanent main building engineering for level 5 , secondary structure for level 5 , temporary buildings for level 5 .

\subsection{The Layout of Surveying Line and Collect Data}

In field investigation the five conditions of exit section the leakage gradient less than the allow leakage gradient $\mathrm{J}=0.45$. It shows that the leakage stability of the dam is satisfied with the requirement of the standard and will not occur leakage failure. But it is still found that there are two leakage areas in the downstream of the dam. La Youting five survey lines that each survey line using 60 electrodes and the electrode spacing is $1 \mathrm{~m}$ in the downstream slope. Electrode made of copper that connects the host through a cable with 32 core, the measurement controlled by program-controlled multichannel conversion switch in the host that also equipped with a RS232 interface and a LCD screen $160 \times 128$ pixels. Putting electrodes into the dam accuracy with tape to make sure contact with it well. The horizontal spacing of each survey line is $3 \mathrm{~m}$, which is layouted in parallel [11], as shown in Figure 1 and Figure 2.

The test data are collected by duk-2b high-density electrical instrument, and combined with the terrain condition select Werner array, each survey line under the condition of Wenner array instrument can collect 552 points and each point can get the voltage, current and the resistivity data, five survey lines obtain 2760 points. Each line near the left bank is set to start electrode 1 , the minimum and maximum isolation coefficient are 1 and 16 .

\subsection{Inversion Results and Analysis}

Putting the data into the computer and calculating the coordinate of each point, then open the software, aftert inverting the test results are shown in Figure 3. Four representative resistivity horizontal sections are selected. In the fifth and sixth layer of the shallow depth, two low resistivity zones can be found in the downstream slope and in depth of the ninth and tenth layer, we can find that there is a low resistivity area inside the dam, there is a oblique channel speculated that lead to the downstream slope in the deep interior of the dam.

In the direction along the dam axis, the resistivity distribution is shown in Figure 4. After the each survey line with the topography, the actual situation of the resistivity distribution of the dam can be more accurately

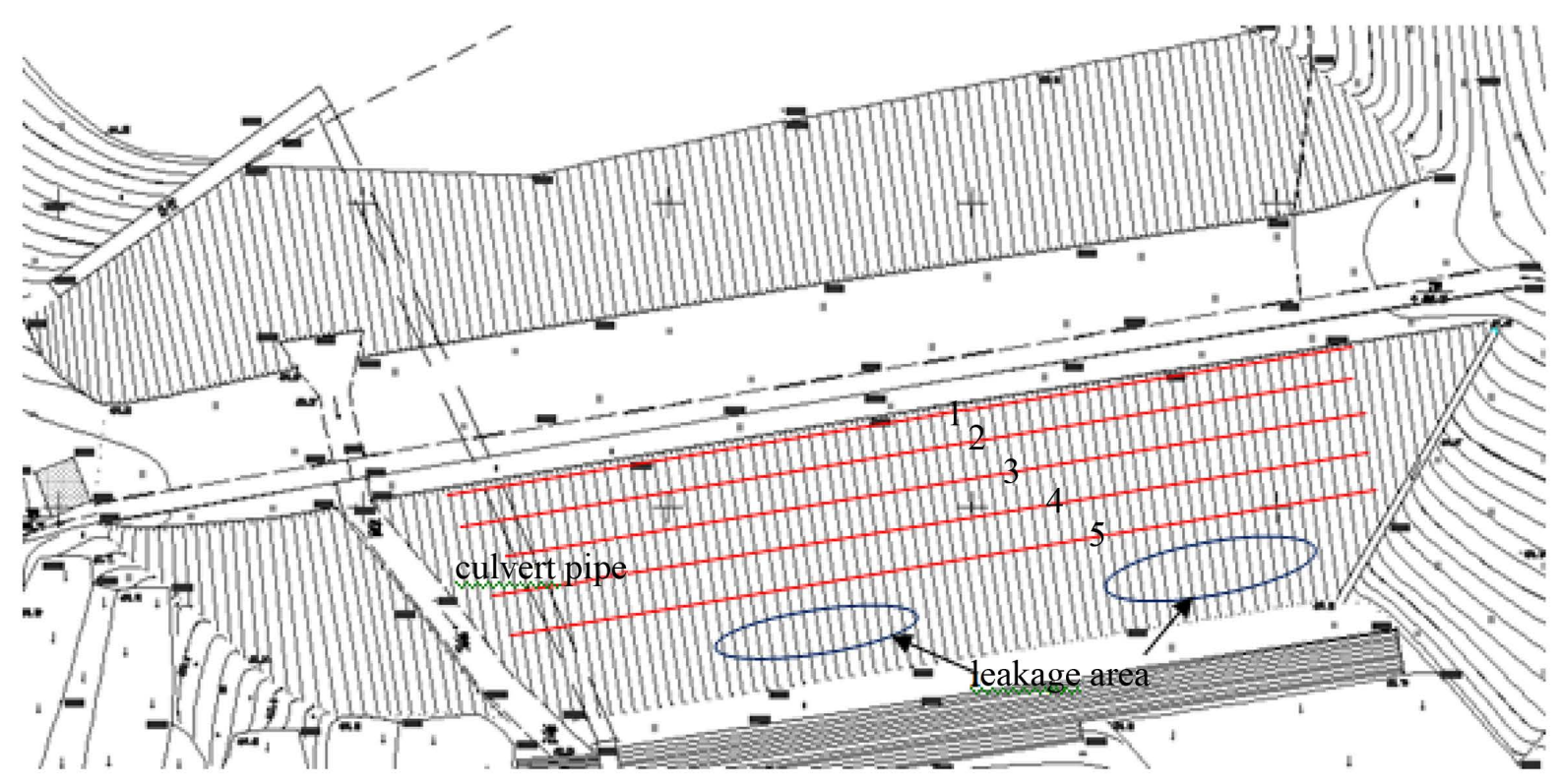

Figure 1. The layout of surveying line. 


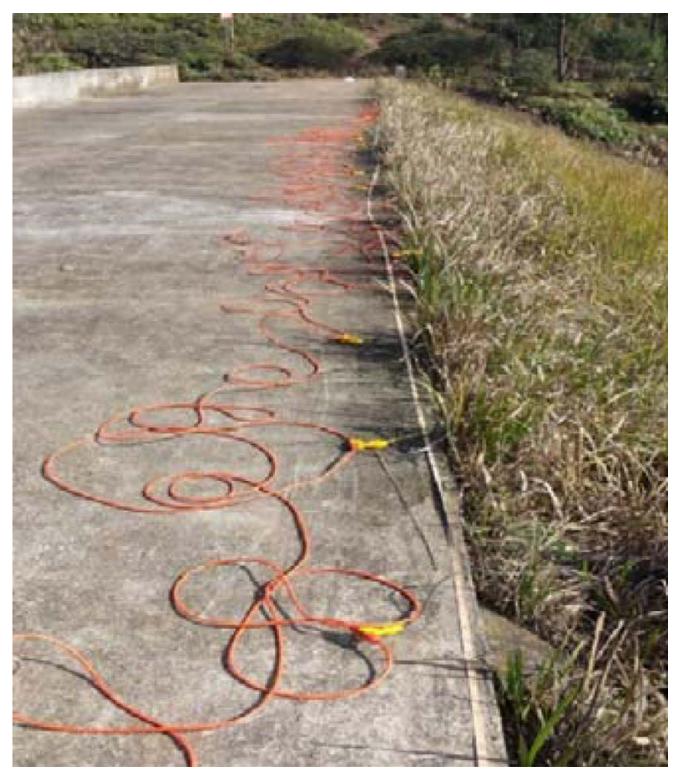

Figure 2. The measurement in field.
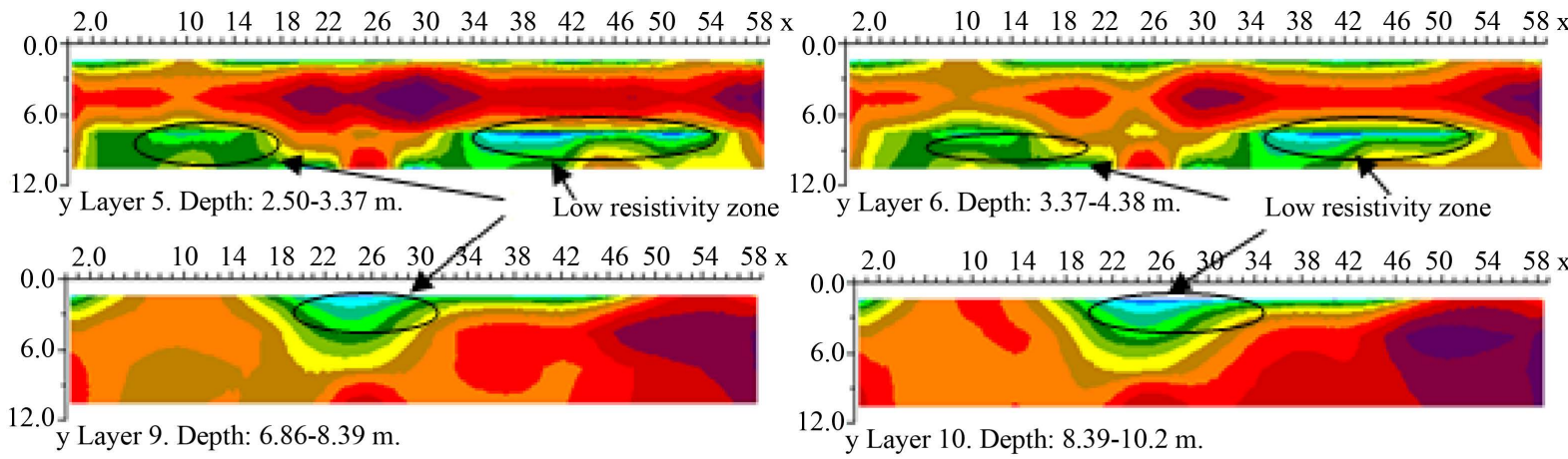

y Layer 6. Depth: $3.37-4.38 \mathrm{~m}$. $\quad$ Low resistivity zone
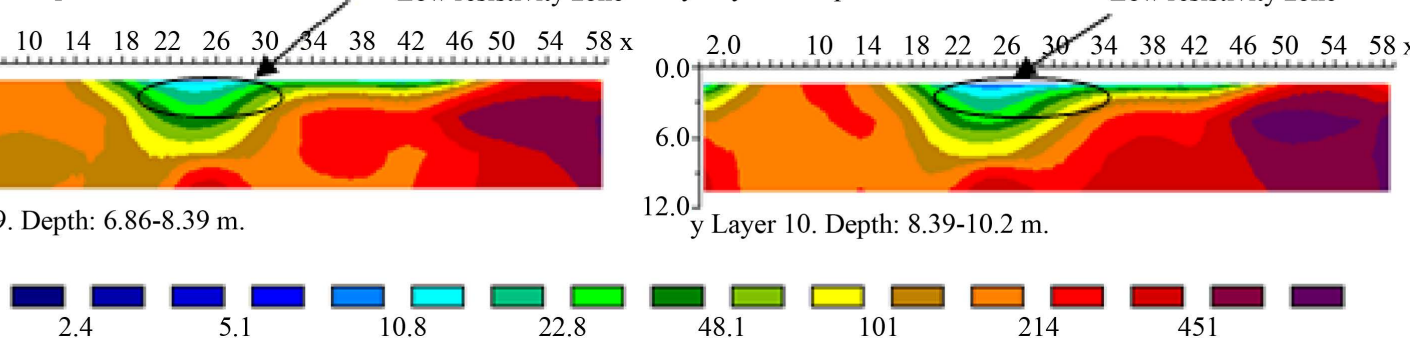

Figure 3. The resistivity of horizontal section XY.
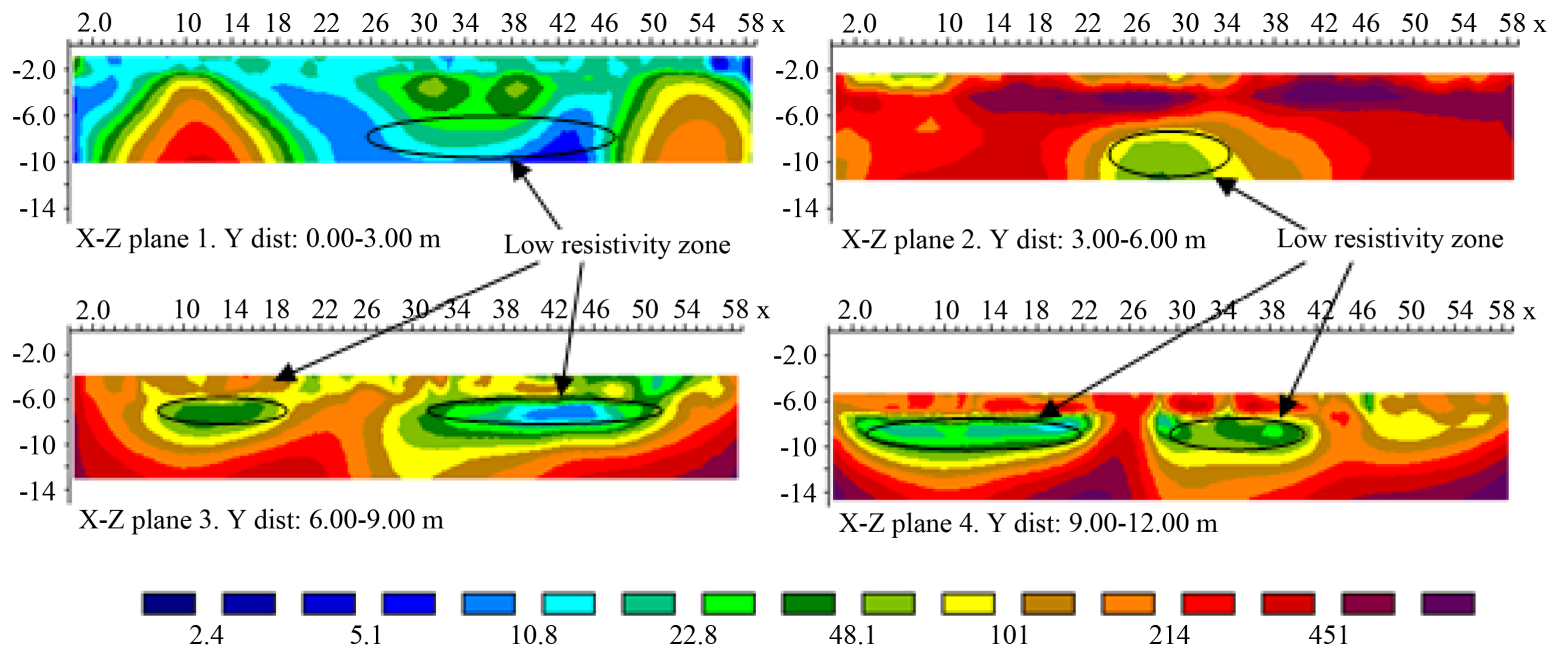

101

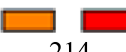

Figure 4. The resistivity along the dam axis section XZ (topography). 
reflected. We can find low resistivity area is wide that shows the leakage seriously in deep inside dam in the first layer resistivity profile. From the inside to the outside, we can find that there are two low resistivity zones in the third layer and fourth layer resistivity profile, the two low resistivity zones in the fourth layer resistivity profile is basically consistent with the leakage area of the downstream slope. It shows that again there is an inclined channel to the downstream slope.

Selecting three resistivity profiles in the direction of the vertical axis as shown in Figure 5 . Three layers lower left part has a low resistivity zone obviously that indicates a wide range of leakage in the dam. It is found that there is a narrow and low resistivity area in the thirty-first layer, but in the thirtieth layer and thirty-second layer low resistivity area are not continuity, it shows that there is an oblique upward channel lead to the downstream slope in the deep interior of the dam.

\section{Discussion}

Two low resistivity zones can be found in the fourth layer of Figure 4, which is consistent with the actual situation, but only one leakage channel is found in Figure 5. In order to further understand the actual situation of the internal leakage channel of the dam by processing the images. Putting the inversion of the data into the image processing software and making into 3D resistivity image as shown in Figure 6, and then using the volume rendering technology for processing the image, through the data conversion and grid processing establish the relationship between the data and model, using volume rendering function, by means of adjusting the color until only shows the blue region. the results show that after rotating angle in Figure 7. The blue area caused by leakage in Figure 7, the leakage area near the downstream slope of the left bank is caused by leakage of deep inside the dam that there is an oblique upward leakage channel [12]. In order to find the cause leakage channel of leakage areas close to the right bank of the downstream slope, that strengthen the volume rendering by adjusting the color range and found that near the right bank inside of the dam has a upward leakage channel in Figure 8, there is a culvert pipe through the dam combined with dam plan, it is predicted that the culvert pipe took place leakage phenomenon caused the leakage areas in the downstream slope.

\section{Conclusions}

1) The 3D electrical resistivity tomography can be used to understand the development of the leakage channel

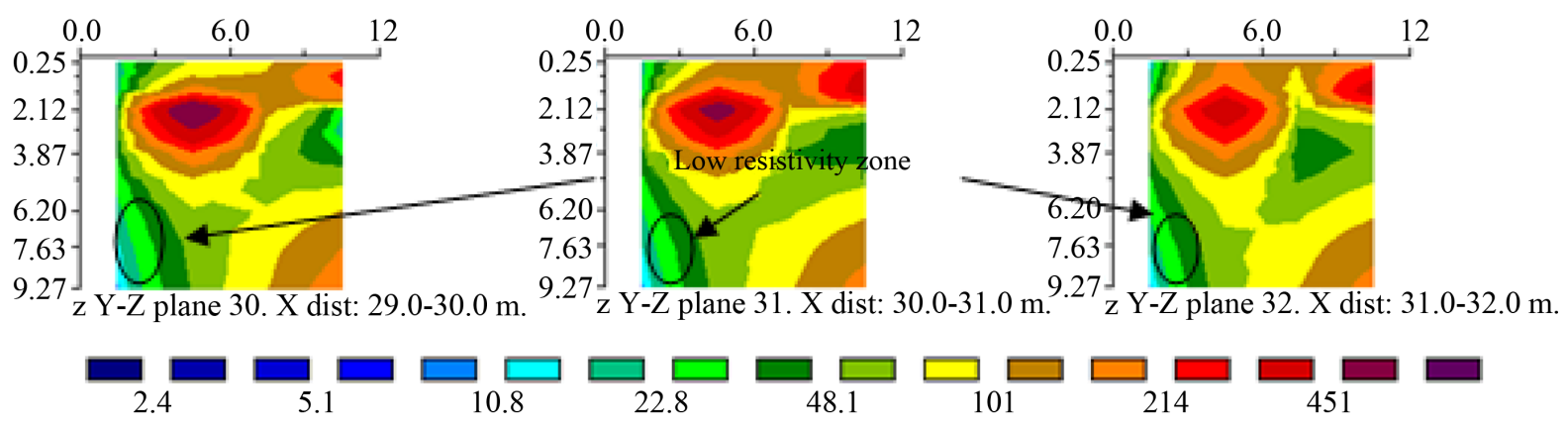

Figure 5. The resistivity of vertical section along dam axis YZ.

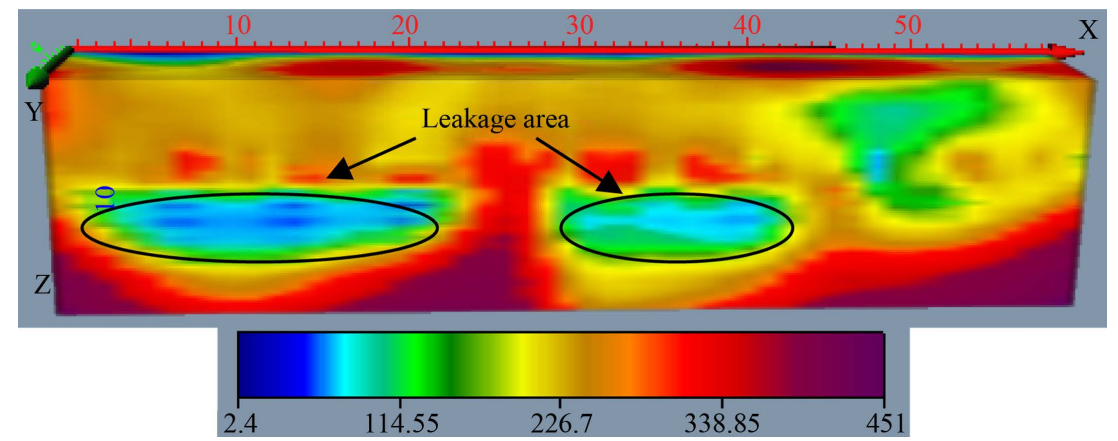

Figure 6. The 3D resistivity image. 


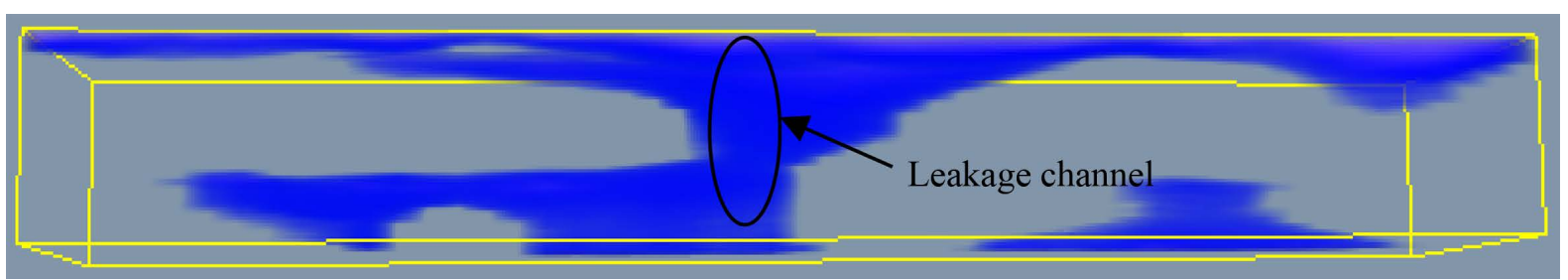

Figure 7. The processing results of volume rendering.

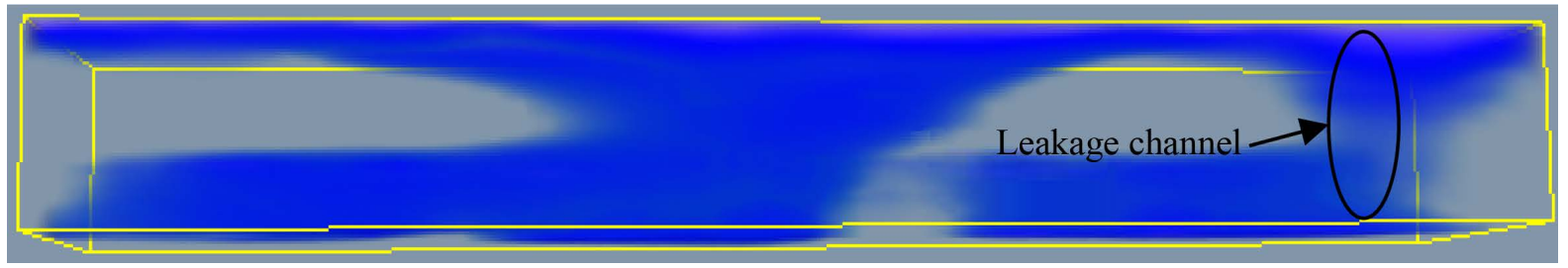

Figure 8. Strengthen the processing results of volume rendering.

and the diagnosis effect is good when earth rock-fill dam is leaking.

2) In the analysis of the leakage channel in earth rock-fill dam use of volume rendering image processing technology, to further understand the spatial form of the leakage and provide help to find leakage.

3) 3D electrical resistivity tomography in the application can provide a wealth of data. The results are intuitive, easy to explain and the results are valid. 3D electrical resistivity tomography will be more widely used in the future.

\section{Acknowledgements}

This paper is funded by National Natural Science Foundation of China (51279219).

\section{References}

[1] Loke, M.H. and Barker, R.D. (1996) Rapid Least-Squares Inversion of Apparent Resistivity Pseudosections Using a Quasi-Newton Method. Geophysical Prospecting, 44, 131-152. http://dx.doi.org/10.1111/j.1365-2478.1996.tb00142.x

[2] Feng, R.., Li, X.Q., Tao, X.L., Sun, C.C., Liu, X.Q. and Hao, J.Q. (1997) Electrical Resistivity Tomography for Hydrogeological Exploration. Acta Seismologica Sinica, 19, 655-663.

[3] Chambers, J.E., Wilkinson, P.B., Penn, S., Meldrum, P.I., Kuras, O., Loke, M.H., et al. (2013) River Terrace Sand and Gravel Deposit Reserve Estimation Using Three-Dimensional Electrical Resistivity Tomography for Bedrock Surface Detection. Journal of Applied Geophysics, 93, 25-32. http://dx.doi.org/10.1016/j.jappgeo.2013.03.002

[4] Zhou, X.X. (2009) Preliminary Study on 3D Resistivity Tomography Application. Chinese Journal of Engineering Geophysics, 6, 549-555.

[5] Shi, L.Q., Zhai, P.H., Wei, J.C., Zhu, L., Han, J. and Yin, H.Y. (2008) Application of 3D High Density Electrical Technique in Detecting the Water Enrichment of Strata. Journal of Shandong University of Science and Technology, 27, 1-4.

[6] Zhao, M.J., Yu, D. and Zhao, H.Y. (2012) Experimental Study on Velocity and Resistivity Combined Tomography for Diagnosing Leakage in Earth Rock-Fill Dam. Journal of Hydraulic Engineering, 43, 118-126.

[7] Luan, Y., Zhao, M.J. and Wang, K. (2010) Analysis of Diseased Earth-Rock Fill Dam Seepage Based on Coupled Fluid-Solid Theorem. Journal of Chongqing Jiaotong University (Natural Science Edition), 29, 741-799.

[8] Li, J.M. (2005) Electric Field and Electric Prospecting. Geological Publishing House, Beijing.

[9] Yang, J.F., Deng, J.Z., Chen, H. and K, H.Y. (2012) 3D Direct Resistivity Forward Modeling by the Precondition Conjugate Gradient Method. Geophysical Geochemical Exploration, 34, 303-309.

[10] Liu, B., Nie, L.C., Li, S.C. Xu, L., Liu, Z.Y., Song, J., et al. (2012) 3D electrical Resistivity Inversion Tomography with Spatial Constraint. Chinese Journal of Rock Mechanics and Engineering, 31, 2258-2268.

[11] Zhang, C.Q., Yang, F., Tan, L. Wu, R.X. and Zhang, P.S. (2014) An Experimental Study on Dual Roadways 3D Parallel Electric Method Numerical and Physical Models. Coal Geology of China, 26, 60-68. 
http://dx.doi.org/10.1016/j.coal.2014.09.002

[12] Guo, G.X. (2011) Voxler-Aided 3D-Interpretation of Electric Sounding Data in Pinggu Basin. Geophysical Geochemical Exploration, 33, 318-322. 